DOI: 10.12731/2070-7568-2020-1-95-107

УДК 338.5

\title{
ПОВЫШЕНИЕ КОНКУРЕНТОСПОСОБНОСТИ ПРЕДПРИЯТИЯ ПОСРЕДСТВОМ ИННОВАЦИОННОГО МАРКЕТИНГА
}

Крылова Т.В., Селиверстова Ю.А., Бердникова А.И., Морозов Д.Л.

В современных экономических условиях конкурентоспособный потенциал предприятия во многом зависит от инноваций. Приоритетным направлением развития современных российских предприятий является активное использование маркетингового подхода в процессе организации их деятельности. Инновационный маркетинг является эффективным и мощным средством развития современного управления.

Целью данного исследования является разработка рекомендаций по повышению конкурентоспособности предприятия на основе внедрения приемов инновачионного маркетинга.

Метод или методология проведения работы: в процессе осущеествления исследования использовались системныйметод, общенаучные методы, эмпирического наблюдения, а такэе экономикостатистического анализа.

Результаты: в данном исследовании подробно рассмотрена сущность и особенности организации инновационной маркетинговой деятельности, предложены конкретные приемы инновачиионного маркетинга, направленные на повышение конкурентоспособности предприятия, занимающегося установкой пластиковых окон.

Область применения результатов: полученные результать исследования помогут руководству предприятия повысить конкурентоспособность организации за счет внедрения инструментов инновационного маркетинга.

Ключевые слова: маркетинг; инновации; инноваџионный маркетинг; конкурентоспособность; предприятие. 


\title{
IMPROVING THE COMPANY'S COMPETITIVENESS THROUGH INNOVATIVE MARKETING
}

\author{
Krylova T.V., Seliverstova Y.A., \\ Berdnikova A.I., Morozov D.L.
}

In modern economic conditions, the competitive potential of an enterprise largely depends on innovation. The priority area for the development of modern Russian enterprises is the active use of the marketing approach in the process of organizing their activities. Innovative marketing is an effective and powerful tool for the development of modern management.

The purpose of this study is to develop recommendations to improve the competitiveness of the enterprise through the introduction of innovative marketing techniques.

Method or methodology of the work: during research used the system method, General scientific methods, empirical observation, as well as economic and statistical analysis.

Results: in this study, the essence and features of the organization of innovative marketing activities are examined in detail, specific innovative marketing techniques aimed at increasing the competitiveness of an enterprise engaged in the installation of plastic windows are proposed.

Scope of the results: the results of the study will help the enterprise management to increase the competitiveness of the organization through the introduction of innovative marketing tools.

Keywords: marketing; innovation; innovative marketing; competitiveness; company.

\section{Введение}

Развитие товарно-денежных отношений в России привело к образованию рынка, насыщенного товарами - «рынка покупателя», когда по большинству групп товаров предложение превышает спрос. Это касается как продукции производственного назначения, так и товаров широкого спроса. Развиваются конкуренция и состязательность 
рыночного процесса. Эффективно разработанная и реализованная маркетинговая кампания позволяет прочно занять свою рыночную нишу, обеспечить конкурентоспособность и максимальную прибыль для предприятия.

Так как отношения между субъектами рыночных отношений становятся более многообразными, изменчивыми и противоречивыми, постоянно усложняются, значимость маркетинга постоянно растет. Необходимым шагом в урегулировании этих отношений является комплексное исследование рынка и его составляющих, которое позволяет снизить риск при принятии управленческих решений и избежать ошибок. Следовательно, актуальными становятся исследования, направленные на изучение рынка, его сегментацию, анализ потребительских предпочтений, продвижению брендов и поддержание эффективных маркетинговых решений.

Целью данного исследования является разработка рекомендаций по повышению конкурентоспособности предприятия на основе внедрения приемов инновационного маркетинга.

На основе анализа теоретических подходов к проблеме разработки и реализации инновационного маркетинга на предприятии, поставлены направления и задачи, решаемые в ходе данного исследования:

- проанализировать современные подходы к разработке и внедрению приемов инновационного маркетинга;

- выявить основные направления повышения конкурентоспособности предприятия за счет реализации инновационной маркетинговой деятельности;

- разработать конкретные приемы инновационного маркетинга для предприятия, занимающегося установкой пластиковых окон.

Аналогичные маркетинговые исследования способствуют решению вопросов, обусловленных оценкой рыночных перспектив товаров и услуг, оценкой результативности предприятия на рынке, изучением изменений потребительских предпочтений, разработкой эффективных способы конкурентной борьбы и принятием обоснованных маркетинговых решений. 


\section{Материалы и методы исследования}

Исследование влияния инновационного маркетинга на конкурентоспособность предприятия проводилось на базе ИП «Белоусов С.П.», занимающегося установкой пластиковых окон, расположенном в г. Н. Новгороде.

Теоретической базой данного исследования послужили труды зарубежных и отечественных ученых в области общей теории маркетинга, основным из которых является Ф. Котлер [2].

В рамках формирования выводов и практических рекомендаций данного исследования, применялись некоторые положения работ Б.Б. Акаева, А.П. Кузнецовой, Н.В. Митропольской-Родионовой, А.А. Урусовой, исследовавших специфику инновационного маркетинга на предприятии $[5,9,11,15]$.

В рамках достоверности полученных теоретических выводов и практических результатов применялись общенаучные методы: монографического анализа, сравнения, абстрактно-логический, а также методы описательной статистики.

\section{Результаты исследования и их обсуждение}

Данное Ф. Котлером определение маркетинга как философии современного предпринимательства выделяет главным образом его высокую социальную роль и оправданность его целей [2]. Это выражается в предоставлении потребителю предельно широкого выбора, повышении качества жизни и уровня потребления, достижении наибольшей потребительской удовлетворенности.

Несомненно, предприниматель стремится к насыщению потребностей целевого рынка, чтобы в итоге обеспечить устойчивое функционирование предприятию в условиях жесткой конкуренции при меняющихся рыночных условиях, следовательно, получает экономическую выгоду, постоянно заботясь о потребителе [12].

Согласно исследованиям Т.Е. Лебедевой управление маркетингом на предприятии должно осуществляться с учетом непрерывного целенаправленного подстраивания маркетинговой деятельности организации под требования рынки с целью установления, укрепления 
и поддержания выгодных обменов с целевыми покупателями для последующего получения прибыли [10].

По мнению Б.Б. Акаева, А.П. Кузнецовой, Н.В. МитропольскойРодионовой, А.А. Урусовой, исследовавших специфику инновационного маркетинга на предприятии, осуществление инновационной маркетинговой деятельности в организации является эффективным и мощным средством развития современного управления [5, 9, 11, 15$]$.

Инновационный маркетинг подразумевает использование творческих подходов во всех видах деятельности организации, направляет на непрерывный поиск новых идей, их введение в деятельность предприятия с целью совершенствования технологий и обеспечения конкурентоспособности продуктов.

Соглашаясь с исследованиями А.П. Кузнецовой, считаем необходимым руководству современных предприятий при разработке корпоративной конкурентной стратегии, опираться на основные принципы инновационной маркетинговой деятельности, которая, по-нашему мнению, должна выступать одной из составляющих единого процесса управления предприятием [9].

Таким образом, инновационный маркетинг отличается своей глубокой стратегической направленностью, что подразумевает не только продвижение готовых нововведений на рынок, но и управление процессом разработки и реализации инноваций, удовлетворяющих потребностям рынка.

Выделим основные отличия инновационного маркетинга:

- применение инновационного маркетинга на протяжении всего процесса управления инновационной деятельностью, включая поиск и удовлетворение новых потребительских предпочтений, а не только продвижение готовых инноваций;

- организация и управление инновационной деятельностью предприятия осуществляется в тесном сотрудничестве и кооперации с рынком, что подразумевает применение сетевой теории и анализ результативных форм взаимоотношений на рынке инноваций;

- предметом исследования и товаром на инновационном рынке является идея, а не готовый продукт [6]. 
Поэтому основной целью инновационного маркетинга является разработка и реализация инновационной стратегии деятельности организации, направленной на увеличение конкурентоспособности предприятия.

В рамках данного исследования была изучена деятельность ИП «Белоусов С.П.», осуществляющего установку пластиковых окон в г. Н. Новгороде, выявлена возможность повышения конкурентоспособности данного предприятия за счет внедрения инновационного маркетинга.

В результате исследования было выявлено, что в настоящее время в ИП «Белоусов С.П.» отсутствует отдел маркетинга, частично деятельностью по продвижению данного предприятия занимается руководитель ИП «Белоусов С.П.». В следствии чего исследуемое предприятие не занимает лидирующих позиций на рынке пластиковых окон, объемы продаж держаться на среднем уровне, инициативы одного только директора не хватает для поддержания предприятия на достойном экономическом уровне, сбытовая, ценовая политика выстроены не эффективно.

С целью усиления своей рыночной позиции на региональном рынке ИП «Белоусов С.П.» были разработаны и предложены к внедрению следующие приемы инновационного маркетинга: мобильный маркетинг, вирусный маркетинг, блоггинг, crazy PR, трайвертайзинг, сенситивный маркетинг, флэшмоб, mirror-TV, сторителлинг (таблица 1).

Таблицуа 1.

Инструменты инновационного маркетинга [12]

\begin{tabular}{|l|l|}
\hline \multicolumn{1}{|c|}{ Название } & \multicolumn{1}{c|}{ Описание } \\
\hline $\begin{array}{l}\text { мобильный } \\
\text { маркетинг }\end{array}$ & $\begin{array}{l}\text { использование возможностей мобильного телефона } \\
\text { посредством SMS/MMS-маркетинга, включающего } \\
\text { как обычные рекламные SMS/MMS-сообщения, так и } \\
\text { разнообразные SMS/MMS-акции }\end{array}$ \\
\hline $\begin{array}{l}\text { вирусный } \\
\text { маркетинг }\end{array}$ & $\begin{array}{l}\text { разнообразные методы распространения информации о } \\
\text { бренде товаре и предприятии, которые характеризуются } \\
\text { информациему идеей целевой аудитории поделиться }\end{array}$ \\
\hline
\end{tabular}


Окончание табл. 1.

\begin{tabular}{|l|l|}
\hline $\begin{array}{l}\text { блог-маркетинг } \\
\text { (блоггинг }\end{array}$ & $\begin{array}{l}\text { продвижение информации о бренде, товаре и предприятии с } \\
\text { помощью использования внимания и возможностей интернет- } \\
\text { сообществ }\end{array}$ \\
\hline сrazy РR & $\begin{array}{l}\text { привлечение внимания целевой аудитории с помощью яркого, } \\
\text { необычного, впечатляющего приема в рекламе }\end{array}$ \\
\hline трайвертайзинг & $\begin{array}{l}\text { кратковременное, безвозмездное использование товара или } \\
\text { услуги с целью ознакомления с его возможностями }\end{array}$ \\
\hline $\begin{array}{l}\text { сенситивный } \\
\text { маркетинг }\end{array}$ & $\begin{array}{l}\text { продвижение товара или услуги за счет использования } \\
\text { визуализации, обоняния, осязания, вкусовых рецепторов и т.д. }\end{array}$ \\
\hline флэшмоб & $\begin{array}{l}\text { предварительно подготовленное массовое мероприятие, } \\
\text { представляющая собой появление большого количества } \\
\text { людей в общественном месте, выполнение ими определенных } \\
\text { действий с последующим быстрым завершением акции }\end{array}$ \\
\hline тіrror-ТV & $\begin{array}{l}\text { размещение зрительного рекламного сообщения в зеркале, } \\
\text { установленное в общественных местах }\end{array}$ \\
\hline сторителлинг & $\begin{array}{l}\text { распространение информации о бренде, товаре и предприятии } \\
\text { посредством поиска смыслов в процессе рассказывания } \\
\text { случаев и различных историй }\end{array}$ \\
\hline
\end{tabular}

Так использование сторителлинга специалистами ИП «Белоусов С.П.» предполагает наличие у специалиста по замеру парытройки интересных случаев из своей практики, умение его интересно такие истории преподнести, эмоционально, с юмором. Цель таких методов - расположить клиента к себе, создать позитивную, доброжелательную обстановку, обратить на себя внимание, оставить неповторимое впечатление. Специалисту ИП «Белоусов С.П.» необходимо уметь общаться, владеть грамотной речью, использовать в своей речи профессиональную терминологию, и в тоже время при необходимости технически сложные моменты пояснять на простом бытовом языке, используя наглядные примеры.

Также в качестве одного из примеров приема инновационного маркетинга может быть размещение рекламы в кабинете стоматолога на окне.

Как правило, кресло пациента в стоматологии всегда стоит напротив окна. Клиент, ожидая, пока врач сделает все необходимые записи в личной карточки больного, сидит и разглядывает кабинет, стены, окно. А если с пациентов проделаны медицинские манипуляции и он вынужден сидеть с открытым ртом, чтобы подейство- 
вало лекарство, застыл раствор и т.д., то конечно же первое на что падает взгляд - это окно. Поэтому предлагаем разместить рекламу с креативным слоганом на окне кабинета стоматолога.

Слоган может быть примерно таким: «Хотите, чтобы на Ваши окна тоже смотрели с открытым ртом, обращайтесь...»

Смело, креативно, инновационно, малозатратно - вот основные преимущества такой рекламы, которая, несомненно, повысит продажи на предприятии.

Следует отметить, что руководству ИП «Белоусов С.П.» необходимо также не игнорировать возможности традиционных инструментов маркетинга, таких как physical evidence из комплекса маркетинга 7P.

Так специалисты по монтажу ИП «Белоусов С.П.» должны иметь спецодежду, желательно с логотипами предприятия. Спецодежда должна быть опрятной, чистой. Рабочий инструмент необходимо хранить в надлежащем виде.

Монтаж окна - самый ответственный этап, поскольку именно он показывает качество и весь производственный процесс предприятия. В процессе демонтажа и монтажа оконных конструкций также необходимо общение с клиентами, если сам клиент нуждается в таком общении. Можно давать разъяснения проводимых работ. После демонтажа и монтажа оконных конструкций остается очень много мусора. Мы рекомендуем проводить уборку после проводимых работ. Времени это займет не очень много, зато впечатление, оставленное после себя, сохранит надолго. Клиент останется в чистой комнате с новым окном.

\section{Заключение}

Актуальность применения инновационного маркетинга на предприятии обуславливается его глубокой стратегической направленностью, что подразумевает не только продвижение готовых нововведений на рынок, но и управление процессом разработки и реализации инноваций, удовлетворяющих потребностям рынка.

Инновационный маркетинг является эффективным и мощным средством развития современного управления, подразумевающим 
использование творческих подходов во всех видах деятельности организации, направляя на непрерывный поиск новых идей, их введение в деятельность предприятия с целью совершенствования технологий и обеспечения конкурентоспособности продуктов.

Поэтому руководству современных предприятий при разработке корпоративной конкурентной стратегии необходимо опираться на основные принципы инновационной маркетинговой деятельности, которая должна выступать одной из составляющих единого процесса управления предприятием.

Аналогичные маркетинговые исследования способствуют решению вопросов, обусловленных оценкой рыночных перспектив товаров и услуг, оценкой результативности предприятия на рынке, изучением изменений потребительских предпочтений, разработкой эффективных способы конкурентной борьбы и принятием обоснованных маркетинговых решений.

\section{Список литературы}

1. Brinker S. Hacking Marketing. Agile Practices to Make Marketing Smarter, Faster, and More Innovative. John Wiley \& Sons Limited, 2016.

2. Kotler Ph., Keller K.L. Marketing management. Prentice Hall, 2011.

3. Mediascope Web Index Report 2017 3. [Электронный ресурс]. URL: http://mediascope.net/services/media/media audience/internet/ information (дата обращения: 19.02.2020).

4. Mobile Marketing Engine Site. [Электронный pecypc]. URL: http:// mobilemarketingengine.com/23-mobile-marketing-stats (дата обращения: 19.02.2020).

5. Акаев Б.Б. Инновационный маркетинг как важная составляющая инновационного менеджмента // Вестник Международного Университета Кыргызстана. 2017. № 3 (33). С. 39-44.

6. Денисова А.Ю. Сущность инновационного маркетинга // Трибуна ученого. 2019. № 6. С. 50-52.

7. Закирова О.В., Перова Т.В. Кросс-маркетинг в продвижении туристских услуг // Вестник Мининского университета. 2015. № 3 (11). С. 6. 
8. Инновационный маркетинг: учебник для бакалавриата и магистратуры / Под общ. ред. С.В. Карповой. М.: Издательство Юрайт, 2018. $457 \mathrm{c}$.

9. Кузнецова А.П. Инновационный процесс в маркетинге как объект управления // News of Science and Education. 2019. Т. 6. № 1. С. 47-57.

10. Лебедева Т.Е. Основы маркетинга: учебно-методическое пособие / Нижний Новгород, 2008.

11. Митропольская-Родионова Н.В. Инновационный маркетинг как инструмент конкурентоспособного бизнеса // Журнал исследований по управлению. 2019. Т. 5. № 1. С. 16-24.

12. Перова Т.В. Планирование и организация маркетинговой деятельности: учебно-методическое пособие / Мининский университет. Нижний Новгород, 2016.

13.Прохорова М.П., Булганина С.В., Емельянова А.М., Сулимова И.Д. Маркетинговое исследование предпочтений клиентов кафе и ресторанов // Наука Красноярья. 2018. Т. 7. № 2-2. С. 99-103.

14. Стратегический маркетинг: учебник и практикум для бакалавриата и магистратуры / Н.П. Реброва. М.: Издательство Юрайт, 2018. 186 с.

15. Урусова А.А. Инновационный маркетинг как особый вид инновационной деятельности // Новая наука: Теоретический и практический взгляд. 2015. № 4. С. 179-181.

16. Якушкина А.А., Иванова И.Г. Инновационный маркетинг как одно из направлений формирования инновационной системы // Colloquiumjournal. 2019. № 9-8 (33). С. 159-161.

17. Яшкова Е.В., Перова Т.В. Внутренний маркетинг как эффективный механизм обеспечения конкурентоспособности организации // Вестник Чувашского университета. 2013. № 2. С. 349-353.

\section{References}

1. Brinker S. Hacking Marketing. Agile Practices to Make Marketing Smarter, Faster, and More Innovative. John Wiley \& Sons Limited, 2016.

2. Kotler Ph., Keller K.L. Marketing management. Prentice Hall, 2011.

3. Mediascope Web Index Report 2017. http://mediascope.net/services/ media/media audience/internet/information (accessed: 19.02.2020). 
4. Mobile Marketing Engine Site. http://mobilemarketingengine.com/23-mobile-marketing-stats (accessed: 19.02.2020).

5. Akaev B.B. Innovatsionnyy marketing kak vazhnaya sostavlyayushchaya innovatsionnogo menedzhmenta [Innovative marketing as an important component of innovation management]. Vestnik Mezhdunarodnogo Universiteta Kyrgyzstana [Bulletin of the International University of Kyrgyzstan], 2017, no. 3 (33), pp. 39-44.

6. Denisova A.Yu. Sushchnost' innovatsionnogo marketinga [The essence of innovative marketing]. Tribuna uchenogo [The rostrum of the scientist], 2019, no.6, pp. 50--52.

7. Zakirova O.V., Perova T.V. Kross-marketing v prodvizhenii turistskikh uslug [Cross-marketing in the promotion of tourist services]. Vestnik Mininskogo universiteta [Vestnik of Minin University], 2015, no. 3 (11), pp. 6.

8. Karpovoy S.V. Innovatsionnyy marketing [Innovative marketing]. Moscow: Izdatel'stvo Yurayt Publ., 2018. 457 p.

9. Kuznetsova A.P. Innovatsionnyy protsess v marketinge kak ob"ekt upravleniya [The innovative process in marketing as an object of management]. News of Science and Education, 2019, T. 6, no. 1, pp. 47-57.

10. Lebedeva T.E. Osnovy marketinga [Marketing basics]. Nizhniy Novgorod: Minin university Publ., 2008. 95 p.

11. Mitropol'skaya-Rodionova N.V. Innovatsionnyy marketing kak instrument konkurentosposobnogo biznesa [Innovative marketing as a tool for competitive business]. Zhurnal issledovaniy po upravleniyu [Management Research Journal], 2019, V. 5, no. 1, pp. 16-24.

12. Perova T.V. Planirovanie i organizatsiya marketingovoy deyatel'nosti [Planning and organization of marketing activities]. Nizhniy Novgorod: Minin university Publ., 2016. 85 p.

13. Prokhorova M.P., Bulganina S.V., Emel'yanova A.M., Sulimova I.D. Marketingovoe issledovanie predpochteniy klientov kafe i restoranov [Marketing research of clients preferences of cafes and restaurants]. Nauka Krasnoyar 'ya [Science of Krasnoyarsk], 2018, V. 7, no. 2-2, pp. 99-103.

14. Rebrova N.P. Strategicheskiy marketing [Strategic marketing]. Moscow: Izdatel'stvo Yurayt Publ., 2018. 186 p. 
15.Urusova A.A. Innovatsionnyy marketing kak osobyy vid innovatsionnoy deyatel'nosti [Innovative marketing as a special type of innovation]. Novaya nauka: Teoreticheskiy i prakticheskiy vzglyad [New Science: Theoretical and Practical Perspective], 2015, no. 4, pp. 179-181.

16. Yakushkina A.A., Ivanova I.G. Innovatsionnyy marketing kak odno iz na-pravleniy formirovaniya innovatsionnoy sistemy [Innovative marketing as one of the directions of the formation of the innovation system]. Colloquium-journal. 2019, no. 9-8 (33), pp. 159-161.

17. Yashkova E.V., Perova T.V. Vnutrenniy marketing kak effektivnyy mekhanizm obespecheniya konkurentosposobnosti organizatsii [Internal marketing as an effective mechanism for ensuring the organization's competitiveness]. Vestnik Chuvashskogo universiteta [Vestnik of Chuvash University], 2013, no. 2, pp. 349-353.

\section{ДАННЫЕ ОБ АВТОРАХ}

Крылова Татьяна Валентиновна, доцент, канд. педагог. наук, доцент ФГБОУ ВО Нижегородский государственный педагогический университет им. К. Минина

ул. Ульянова, 1, г. Нижний Новгород, 603950, Российская Федеращия

perova_tatyana83@mail.ru

Селиверстова Юлия Александровна, доцент, канд. политич. наук, доцент

ФГАОУ ВО «Национальный исследовательский Нижегородский государственный университет им. Н.И. Лобачевского» пр. Гагарина, 23. г. Нижний Новгород, 603950, Российская Федерачия

seliverstova@imomi.unn.ru

\section{Бердникова Анастасия Игоревна, студент}

ФГБОУ ВО Нижегородский государственный педагогический университет им. К. Минина 
ул. Ульянова, 1, г. Нижний Новгород, 603950, Российская Федерачия

Berdnikova_2001_nastena@mail.ru

Морозов Денис Леонидович, студент

ФГБОУ ВО Нижегородский государственный педагогический университет им. К. Минина

ул. Ульянова, 1, г. Нижний Новгород, 603950, Российская Федерачия

denis.morozov.25@yandex.ru

DATA ABOUT THE AUTHORS

Krylova Tatyana Valentinovna, Associate Professor, $\mathrm{PhD}$

Nizhny Novgorod State Pedagogical University

1, Ulyanova Str., N. Novgorod, 603950, Russian Federation

perova_tatyana83@mail.ru

SPIN-code: 4225-3577

ORCID: 0000-0001-9328-9066

ResearcherID: J-6358-2017

Scopus Author ID: 57188857131

Seliverstova Yulia Alexandrovna, Associate Professor, $\mathrm{PhD}$

Lobachevsky State University of Nizhny Novgorod

23, Gagarin Ave., N. Novgorod, 603950, Russian Federation

seliverstova@imomi.unn.ru

ORCID:0000-0003-0356-2933

Berdnikova Anastasia Igorevna, student

Nizhny Novgorod State Pedagogical University

1, Ulyanova Str., N. Novgorod, 603950, Russian Federation Berdnikova_2001_nastena@mail.ru

Morozov Denis Leonidovich, student

Nizhny Novgorod State Pedagogical University

1, Ulyanova Str., N. Novgorod, 603950, Russian Federation denis.morozov.25@yandex.ru 